\title{
Colloidal lithography and Metal-Organic Chemical Vapor Deposition process integration to fabricate $\mathrm{ZnO}$ nanohole arrays
}

\author{
Maria Elena Fragalà ${ }^{a, *}$, Cristina Satriano a, Yana Aleeva ${ }^{b}$, Graziella Malandrino $^{\text {a }}$ \\ a Dipartimento di Scienze Chimiche Università di Catania and INSTM UdR Catania, Viale Andrea Doria,6, Catania, Italy \\ b Scuola Superiore Università di Catania, Dipartimento di Scienze Chimiche Viale Andrea Doria, 6, Catania, Italy
}

\section{A R T I C L E I N F O}

Available online 14 April 2010

Keywords:

$\mathrm{ZnO}$

Catalyst

Nanowires

Nanohole array

Colloidal lithography

MOCVD

\begin{abstract}
A B S T R A C T
A complete set up of optimal process conditions for an effective colloidal lithography/catalyst assisted MOCVD process integration is presented. It mainly focuses on the determination of the deposition temperature threshold for ZnO Metal-Organic Chemical Vapour Deposition (MOCVD) as well as the concentration of metal-organic silver $(\mathrm{Ag})$ catalyst. Indeed, the optimization of such process parameters allows to tailor the ZnO film morphology in order to make the colloidal lithography/catalyst assisted MOCVD approach a valuable bottom up method to fabricate bi-dimensional ordered ZnO nanohole arrays.
\end{abstract}

(C) 2010 Elsevier B.V. All rights reserved.

\section{Introduction}

$\mathrm{ZnO}$ is a multifunctional material having intriguing semiconducting, optical, ferroelectric, piezoelectric, chemical and biochemical properties for a wide range of novel applications [1,2]. In particular $\mathrm{ZnO}$ nanowires and nanorods represent spatially controlled, highly functional nanostructures having remarkable physical and chemical properties [3-6].

$\mathrm{ZnO}$ nanowires can be produced using different metal catalysts and the metal selection is crucial to achieve the desired nanowire morphology and to avoid any potential detrimental contamination [7]. A catalyst particle deposited on a substrate acts as a preferential site for vapour absorption of the desired source material. As the source material is absorbed into the catalyst and the catalyst particle becomes supersaturated, the excess source material precipitates out and a 1D nanostructure grows [8]. Different catalysts can be used [9-11], Au being the most used for $\mathrm{ZnO}$ nanowire growth $[12,13]$. In fact, the use of $\mathrm{Ag}$ as an alternative catalyst has the drawback of temperature limitation (up to $500{ }^{\circ} \mathrm{C}$ ) related to fast $\mathrm{Ag}$ oxidation which results in low-quality nanowires [8]. For this reason $\mathrm{Ag}$ has been much less explored as a catalyst for the growth of $\mathrm{ZnO}$ nanostructures.

On the other hand, the surface nanostructuring of metal oxide films in two-dimensional (2D) porous substrates is an intriguing strategy for various applications including microelectronics, sensing, catalysis, optics and biomedical science $[14,15]$.

\footnotetext{
* Corresponding author. Dipartimento di Scienze Chimiche, Università di Catania Viale Andrea Doria, 6, 95127 Catania, Italy. Tel.: +39 095 7385055; fax: +39095 580138.

E-mail address: me.fragala@unict.it (M.E. Fragalà).
}

In this context, nanosphere lithography is emerging as an effective bottom up and flexible approach where self-assembled 2D colloidal nanoparticles [16] act as template or mask for producing 2D regular and nearly homogenous arrays of the desired materials [17]. Recently we reported on the fabrication of two-dimensional periodic $\mathrm{ZnO}$ arrays by a hybrid approach of colloidal lithography and MOCVD, based on silver catalyst-controlled $\mathrm{ZnO}$ growth [18].

In this paper we focus on optimization of experimental set up with a particular effort dedicated to study the MOCVD temperature deposition threshold and the relationship between initial concentrations of silver catalyst metal-organic precursor and $\mathrm{ZnO}$ deposition process parameters (deposition temperature and time), in order to tailor the morphology of $\mathrm{ZnO}$ films.

X-ray photoelectron spectroscopy and atomic force microscopy analyses are used as valuable methods to define the $\mathrm{ZnO}$ deposition temperature threshold, in terms of both thickness uniformity and film composition. Moreover, the scanning electron microscopy analyses integrate this study by evidencing the relationship between the silver catalyst concentration and the $\mathrm{ZnO}$ morphological control. The obtained results allow to set up the optimal experimental conditions for an effective colloidal lithography/catalyst assisted MOCVD process integration, in order to fabricate bi-dimensional ordered $\mathrm{ZnO}$ nanohole arrays.

\section{Experimental}

ZnO depositions on unpatterned or patterned (via colloidal lithography) silicon substrates have been performed in a hot wall tubular reactor, using a diamine $\left(\mathrm{N}, \mathrm{N}, \mathrm{N}^{\prime}, \mathrm{N}^{\prime}\right.$-tetramethylethylenediamine) adduct of zinc bis- 2 thenoyl-trifluoroacetonate [ $\left.\mathrm{Zn}(\mathrm{tta})_{2} \cdot \mathrm{tmeda}\right]$ [22]. Deposition conditions have been optimized through evaluation of 


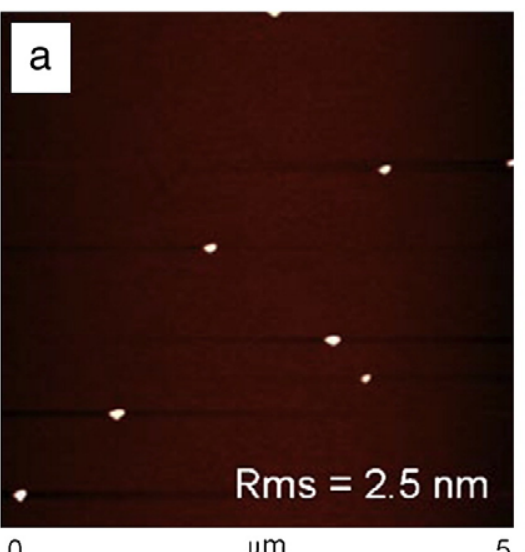

0

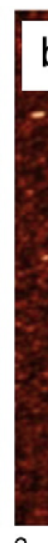

50

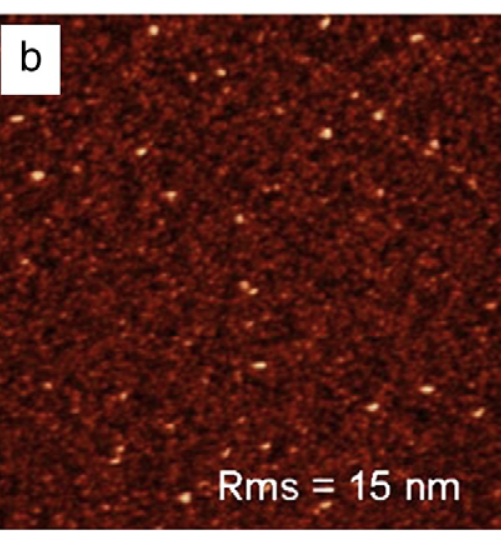

$\mu \mathrm{m}$
50

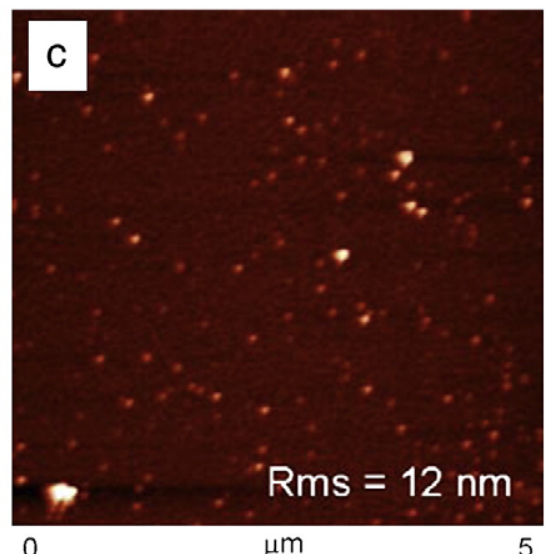

5

Fig. 1. AFM images of bare silicon substrate, before (a) and after $\mathrm{ZnO}$ thin film depositions at $300{ }^{\circ} \mathrm{C}, 40 \mathrm{~min}$ (b) and $400{ }^{\circ} \mathrm{C}, 5 \mathrm{~min}(\mathrm{c})$.

different growth temperatures, (ranging from $250^{\circ}$ to $600^{\circ} \mathrm{C}$ ) and times (ranging from 5 min to $1 \mathrm{~h}$ ).

$\mathrm{Ag}(\mathrm{hfa}) \cdot$ tetraglyme (Hhfa 1,1,1,5,5,5-hexafluoro-2,4-pentanedione; tetraglyme 2,5,8,11,14-pentaoxatetradecane) precursor, whose synthesis has been reported elsewhere $[19,20]$, has been dissolved in Tetrahydrofuran (THF). The obtained solutions, having $0.1 \mathrm{M}$ and $0.01 \mathrm{M}$ concentrations, have been drop casted either on unpatterned or patterned silicon substrates, previously dipped in $\mathrm{HF}\left(7: 1 \mathrm{HF} / \mathrm{H}_{2} \mathrm{O}\right.$ dilution, 1 min dipping time). Patterned silicon substrates have been obtained by dewetting driven self-assembly of polystyrene (PS) nanoparticles into close packed hexagonal arrays [21].

ZnO has been deposited by MOCVD either on silicon and unpatterned $(\mathrm{Ag}(\mathrm{hfa})$ tetraglyme initial concentrations of $0.1 \mathrm{M}$ and $0.01 \mathrm{M})$ or patterned $(\mathrm{Ag}(\mathrm{hfa})$ tetraglyme initial concentration of $0.1 \mathrm{M})$ catalyst layers. $\mathrm{Ar}(150 \mathrm{sccm})$ and $\mathrm{O}_{2}(150 \mathrm{sccm})$ have been used as carrier and reactive gas respectively.

The X-ray photoelectron experiments (XPS) have been carried out with a base pressure of $2 \times 10^{-10}$ Torr using a PHI ESCA/SAM 5600 Multy technique spectrometer. A monochromatic $\mathrm{Al} \mathrm{K}_{\alpha}$ radiation source ( $\mathrm{h} v=1486.6 \mathrm{eV}$ ) has been used. The surface analysis of $\mathrm{ZnO}$ films has been conducted by acquiring both survey and narrow region scans at pass energies respectively of $187 \mathrm{eV}$ and $11 \mathrm{eV}$, with an incremental step size of $1 \mathrm{eV}$ for survey scans and $0.05 \mathrm{eV}$ for the narrow scans, and a $0.8 \mathrm{~mm}$ slit width. Spectra have been acquired at a takeoff angle of $45^{\circ}$ with respect to the samples surface. The samples have been sufficiently conductives that it has been not necessary to

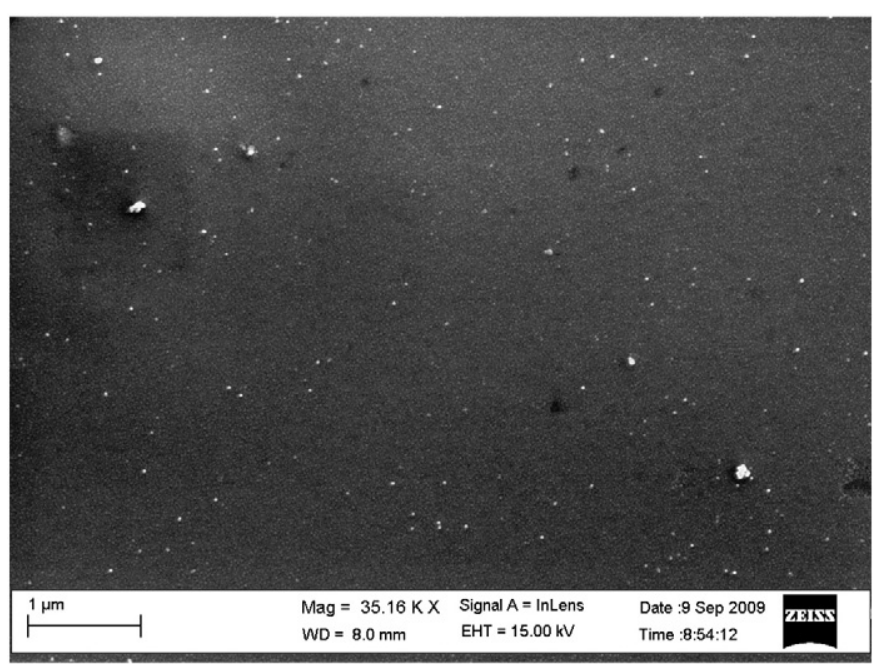

Fig. 2. SEM image (scale bar $=1$ micron) of $\mathrm{ZnO}$ film deposited on $\mathrm{Si}$ at $400{ }^{\circ} \mathrm{C}, 5 \mathrm{~min}$. supply electrons for charge compensation. The XPS signals have been analysed by using a peak synthesis program in which a nonlinear background is assumed and the fitting peaks of the experimental curve have been defined by a combination of gaussian $(80 \%)$ and lorentzian (20\%) distributions. The atomic compositions have been evaluated using sensitivity factors as provided by F V5.4A software.

Film surface morphologies have been investigated using a LEO Supra 55VP field emission gun scanning electron microscope (FEG-SEM).

Atomic force microscopy (AFM) images have been obtained in high amplitude tapping mode in air with an NT-MTD instrument. Golden silicon probes (NT-MTD) with a nominal resonant frequency of $190-325 \mathrm{kHz}$ have been employed.

\section{Results and discussion}

In order to identify the deposition temperature threshold, $\mathrm{ZnO}$ thin films have been deposited at low temperatures (below $450{ }^{\circ} \mathrm{C}$ ) on unpatterned silicon substrates. The AFM images (Fig. 1a-b) show the film morphology of $\mathrm{ZnO}$ films grown respectively at $300{ }^{\circ} \mathrm{C}$ (for 40 min, Fig. 1b) and $400{ }^{\circ} \mathrm{C}$ (for 5 min, Fig. 1c) in comparison with a bare silicon substrate (Fig. 1a). For both deposition conditions, it is evident that, notwithstanding the low temperatures used, the $\mathrm{ZnO}$ thin films are successfully grown on the substrates. The morphology of $300{ }^{\circ} \mathrm{C}, 40 \mathrm{~m}$ (Fig. 1b) deposited films clearly presents spherical grains, having dimensions of about $50 \mathrm{~nm}$. The related overall surface roughness (Rq) is peaked at $\sim 15 \mathrm{~nm}$. The film deposited at $400{ }^{\circ} \mathrm{C}$, $5 \mathrm{~min}$ (Fig. 1b) is characterised by a smoother surface $(\sim 12 \mathrm{~nm})$. Therefore, we deduce that the latter film can be likely constituted by a continuous layer, with isolated large grains, as better visible in the related SEM image (Fig. 2). It is worthy to note that the AFM analysis (not shown) of $\mathrm{ZnO}$ deposited on silicon substrates at $250{ }^{\circ} \mathrm{C}$, reveals the presence of isolated $\mathrm{ZnO}$ islands and confirms a limited deposition.

The AFM analysis is supported by XPS results, showing the typical $\mathrm{Zn} 2 \mathrm{p}_{3 / 2}$ peak centered at $1022 \pm 0.2 \mathrm{eV}$, that validates the presence of the $\mathrm{ZnO}$ layers onto silicon substrates. The average atomic compositions from XPS analysis are reported in Table 1.

It is worthy to note that the $\mathrm{Zn}$ content detected on the $\mathrm{ZnO}$ film deposited at $400{ }^{\circ} \mathrm{C}(\sim 26 \%)$ is higher than that of the films deposited at $300{ }^{\circ} \mathrm{C}(\sim 14 \%)$. However, while the latter film seems

Table 1

XPS average atomic composition of $\mathrm{ZnO}$ films vs deposition temperature.

\begin{tabular}{lrlll}
\hline & Zn & C & O & Si \\
\hline $250{ }^{\circ} \mathrm{C}$ & 1.6 & 21.7 & 39.4 & 37.3 \\
$300{ }^{\circ} \mathrm{C}$ & 14.0 & 52.9 & 33.0 & NA \\
$400{ }^{\circ} \mathrm{C}$ & 25.7 & 23.1 & 48.8 & 7.5 \\
\hline
\end{tabular}




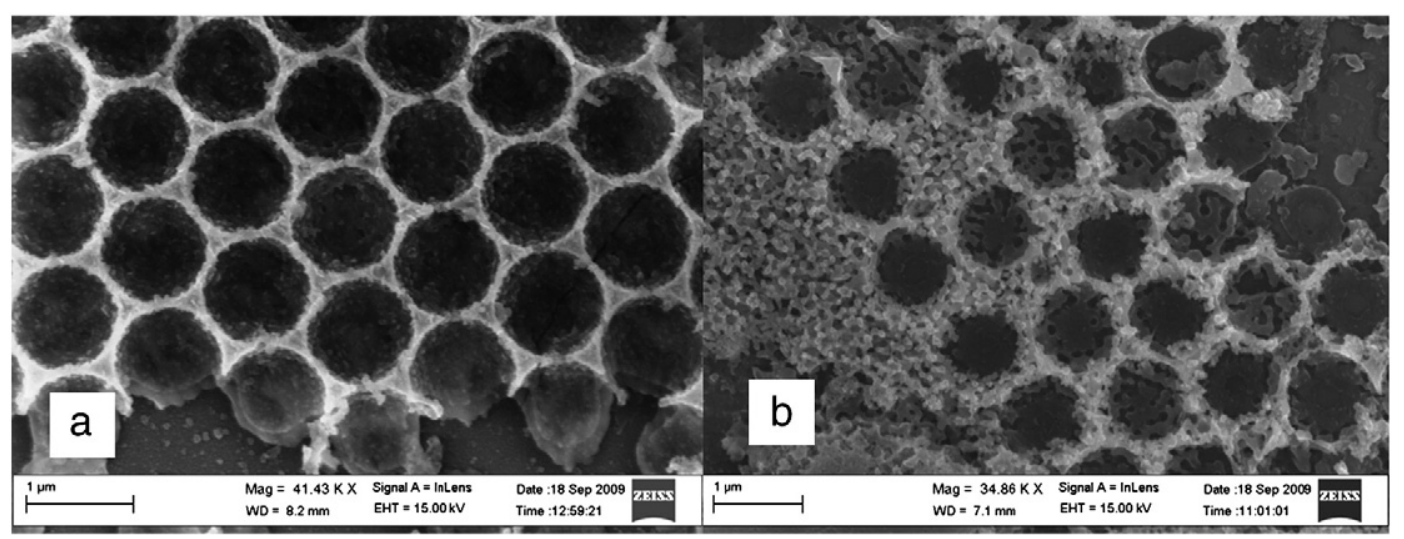

Fig. 3. SEM images (scale bar $=1$ micron) of $\mathrm{ZnO}$ film deposited on Si substrates patterned with PS nanosphere: (a) $300{ }^{\circ} \mathrm{C}, 40 \mathrm{~min},(\mathrm{~b})$ and $400{ }^{\circ} \mathrm{C}, 5 \mathrm{~min}$.

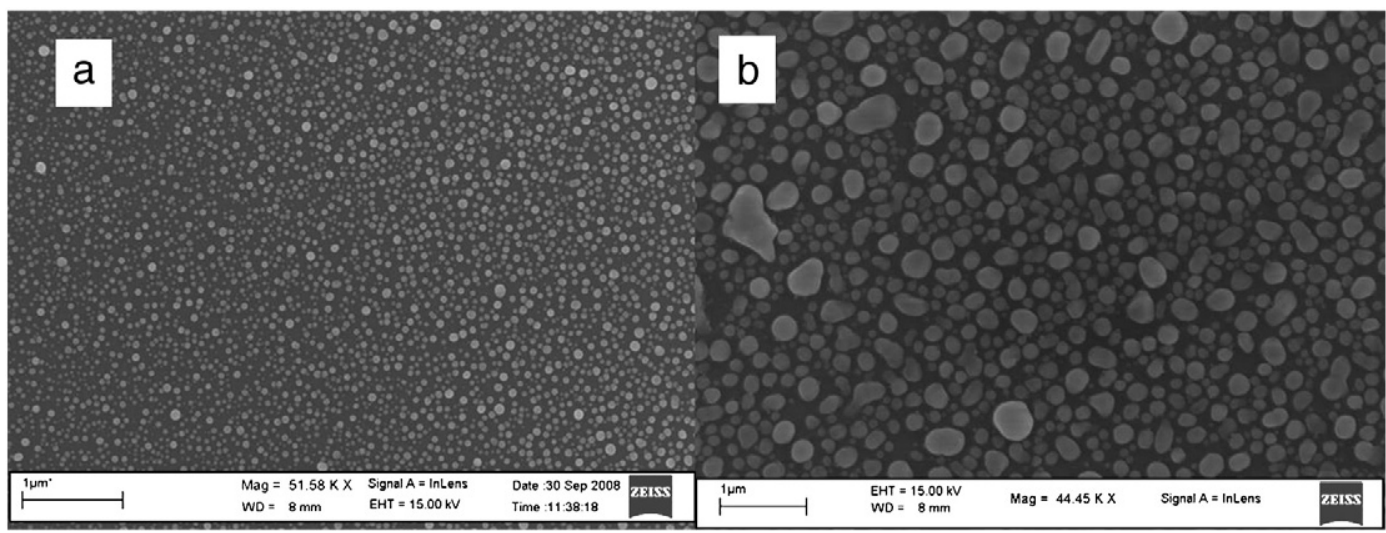

Fig. 4. SEM images (scale bar $=1$ micron) of annealed silver film deposited on Si by spin coating (a) and drop casting (b).

to completely cover the substrate (silicon signal is not detected), on the $\mathrm{ZnO}$ film grown at $400{ }^{\circ} \mathrm{C}$ a silicon content of about $7 \%$ indicates the formation of $\mathrm{ZnO}$ islands. These findings confirm the morphological results of AFM and SEM analyses, i.e., the formation, working at $400{ }^{\circ} \mathrm{C}$ (5 min), of isolated large grains on a continuous film thinner than that deposited at $300{ }^{\circ} \mathrm{C}(40 \mathrm{~min})$. Moreover, the $\mathrm{ZnO}$ film deposited at high temperature $\left(400{ }^{\circ} \mathrm{C}\right)$ shows a reduced carbon content respect with the low temperature sample $\left(300^{\circ} \mathrm{C}\right)$, as expected from a smoother surface as well as from the higher deposition temperature. As to the $\mathrm{ZnO}$ sample deposited at $250{ }^{\circ} \mathrm{C}$, the detected amount of $\mathrm{Zn}$ is very small (about $2 \%$ ). Therefore we can set the MOCVD deposition threshold above the temperature of $250^{\circ} \mathrm{C}$.

By applying the above discussed deposition conditions to deposit $\mathrm{ZnO}$ on silicon substrates patterned by colloidal lithography, the formations of $\mathrm{ZnO}$ nanohole arrays are successfully achieved, as shown in Fig. 3, where the $\mathrm{ZnO}$ nanospheres are obtained both at $300{ }^{\circ} \mathrm{C}, 40 \mathrm{~min}$ (Fig. 3a) and $400{ }^{\circ} \mathrm{C}, 5 \mathrm{~min}$ (Fig. 3b).

Finally, the effect of $\mathrm{Ag}$ catalyst concentrations on deposited $\mathrm{ZnO}$ morphology is discussed. $\mathrm{Ag}$ (hfa)tetraglyme [19] ethanolic solutions ( $0.1 \mathrm{M}$ and $0.01 \mathrm{M}$ ) have been deposited either by drop casting or spin

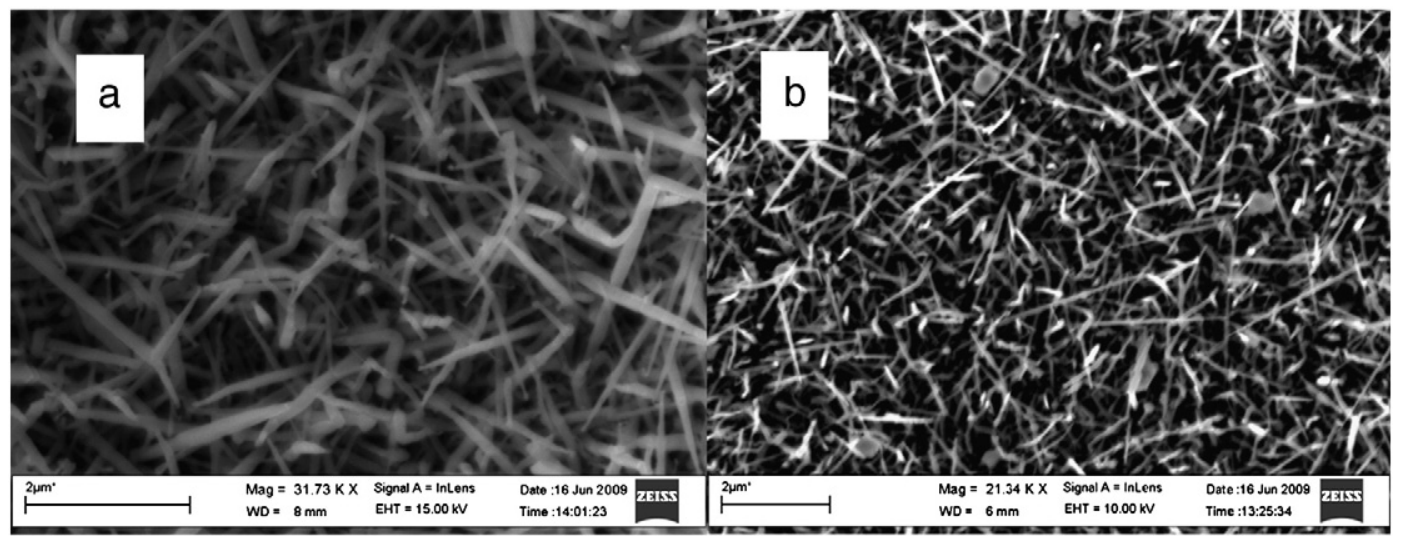

Fig. 5. SEM images (scale bar $=2$ micron) of $\mathrm{ZnO}$ nanowires growth (on silver catalyst) at $600{ }^{\circ} \mathrm{C}$ after 1 hour deposition (a) and 30 min deposition (b). 


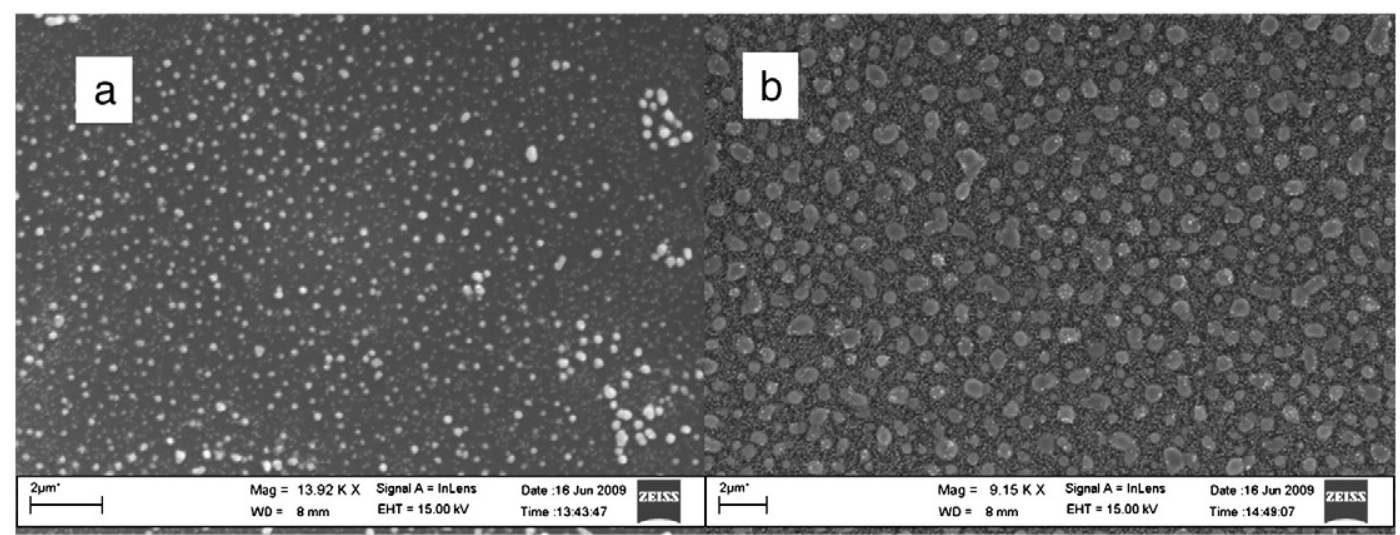

Fig. 6. SEM images (scale bar $=2$ micron) of $\mathrm{ZnO}$ film deposited at $400{ }^{\circ} \mathrm{C}, 30$ minutes on $\mathrm{Ag}$ catalyst layer at the initial concentrations of $0.01 \mathrm{M}$ (a) and $0.1 \mathrm{M}$ (b).

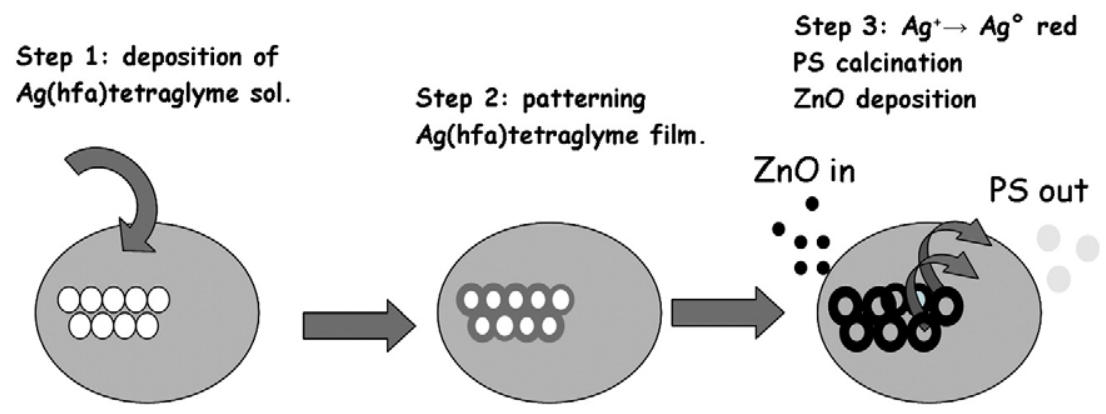

Fig. 7. A schematic representation of the process sequence adopted to fabricate $\mathrm{ZnO}$ ordered nanoholes array.

coating on silicon substrates. A further annealing in air, performed at $400{ }^{\circ} \mathrm{C}$ for $30 \mathrm{~min}$, is used to reduce $\mathrm{Ag}^{+}$ions to metallic silver. The obtained nanostructured films are composed of discrete silver grains, whose dimensions depend on the deposition technique, spin coating vs drop casting (Fig. 4). In fact, the spin coated layers present an average dimensions of about $100 \mathrm{~nm}$ (Fig. 4a), that increase up to $300 \mathrm{~nm}$, for the drop casted ones (Fig. 4b), due to grain coalescence effects.

$\mathrm{ZnO}$ has been deposited by MOCVD on the substrates pre-coated with the silver catalyst films. Different process conditions have been used to study how the catalytic effect can tailor the $\mathrm{ZnO}$ film morphology. A massive $\mathrm{ZnO}$ nanowire production is promoted by high deposition temperature $\left(600^{\circ} \mathrm{C}, 1 \mathrm{~h}\right.$, Fig. 5a) [18], using a $0.01 \mathrm{M} \mathrm{Ag}$ catalyst initial concentration, despite short process deposition times $\left(600{ }^{\circ} \mathrm{C}, 30 \mathrm{~min}\right.$, Fig. 5b). Only at low deposition temperatures, not higher than $400{ }^{\circ} \mathrm{C}$, the ZnO film morphology changes significantly, thus replicating the original catalyst nanostructure. Using these low temperature conditions the overall film morphology appears sensitive to both catalyst initial concentration and $\mathrm{ZnO}$ deposition time (Fig. 6). In fact, after $30 \mathrm{~min}$ of $\mathrm{ZnO}$ deposition on silver catalyst (initial precursor concentration of $0.01 \mathrm{M}$ ) the pristine Ag grains distribution is still visible and no significant $\mathrm{ZnO}$ growth is observed between the grains (Fig. 6a).

On the other hand, a more extensive growth is observed when deposition time is increased up to $60 \mathrm{~min}$ and/or when a higher catalyst precursor concentration $(0.1 \mathrm{M})$ is used (Fig. $6 \mathrm{~b})$.

These findings indicate a strong catalytic effect of the silver metalorganic precursor on $\mathrm{ZnO}$ growth and suggest that a proper tuning of the deposition process parameters (i.e., low catalyst concentrations, deposition temperature below $400{ }^{\circ} \mathrm{C}$, short process time) limits and controls the high yield production of $\mathrm{ZnO}$ nanowires. Moreover, the accurate matching of both catalyst precursor concentrations and $\mathrm{ZnO}$ deposition process conditions is required for an effective integration of catalyst assisted MOCVD process with colloidal lithography (Fig. 7) driving the formation of ordered $\mathrm{ZnO}$ nanoholes array [18].

\section{Conclusions}

The presented results demonstrate an easy route to control the morphology of $\mathrm{ZnO}$ films deposited by MOCVD. Indeed the formation of $\mathrm{ZnO}$ nanowires can be finely tuned through the accurate control of the initial concentration of $\mathrm{Ag}$ catalyst precursor as well as of the $\mathrm{ZnO}$ growth process parameters, such as temperature and deposition time. This process tuning is also required for an effective integration of the MOCVD deposition process with colloidal lithography to obtain ordered $\mathrm{ZnO}$ nanoholes array [18]. The possibility to simply modify both the concentration of metal-organic precursor solutions, easily deposited (spin coating or drop casting) on any kind of substrate and the ZnO MOCVD process conditions, makes the proposed hybrid approach valuable to fabricate nanoporous $\mathrm{ZnO}$ based layers with remarkable high surface areas. Such nanostructures are promising for a wide variety of applications including bioengineering, catalysis, environmental engineering and sensor systems.

\section{Acknowledgements}

Authors acknowledge CNR-ISTM and INSTM within the ALADIN Industria 2015 Project (Ministero dello Sviluppo Economico) for support to the present study.

\section{References}

[1] X. Wang, J. Song, Z.L. Wang, J. Mater. Chem. 17 (2007) 711.

[2] Z.L. Wang, ACS Nano 2 (10) (2008) 1987. 
[3] X. Duan, Y. Huang, Y. Cui, J. Wang, C.M. Lieber, Nature 409 (2001) 66.

[4] Y. Huang, X. Duan, Y. Cui, L. Lauhon, K. Kim, C.M. Lieber, Science 294 (2001) 1313.

[5] J.H. Song, X.D. Wang, E. Riedo, Z.L. Wang, Nano Lett. 5 (2005) 1954.

[6] F. Patolsky, C.M. Lieber, Mater. Today 8 (2005) 20.

[7] Z. Zhang, S.J. Wang, T. Yu, T. Wu, J. Phys. Chem. C 111 (2007) 17500.

[8] M. Kirkham, X. Wang, Z.L. Wang, R.L. Snyder, Nanotechnology 18 (2007) 365304

[9] X. Wang, J. Song, C.J. Summers, J.H. Ryou, P. Li, R.D. Dupuis, Z.L. Wang, J. Phys Chem. B 110 (2006) 7720.

[10] C. Li, G. Fang, Y. Ren, Q. Fu, X. Zhao, J. Nanosci. Nanotechnol. 6 (2006) 1467.

[11] J. Rybczynski, D. Banerjee, A. Kosiorek, M. Giersig, Z.F. Ren, Nano Lett. 4 (10) (2004) 2037

[12] M.H. Huang, Y.Wu, H. Feick, N. Tran, E. Weber, P. Yang, Adv. Mater. 13 (2) (2001) 113.

[13] X. Wang, C.J. Summers, Z.L. Wang, Nano Lett. 4 (2004) 423.
[14] J.H. Moon, W.S. Kim, J.-W. Ha, S.G. Jang, S.-M. Yang, J.-K. Park, Chem. Commun. 32 (2005) 4107.

[15] L.S. McCarty, A. Winkleman, G.M. Whitesides, Angew. Chem. Int. Ed. 46 (2007) 206.

[16] S.-M. Yang, S.G. Jang, D.-G. Choi, S. Kim, H.K. Yu, Small 2 (4) (2006) 458

[17] J.-H. Lee, I.-C. Leu, Y.-W. Chung, M.-H. Hon, Nanotechnology 17 (2006) 4445.

[18] M.E. Fragalà, C. Satriano, G. Malandrino, Chem. Commun. 7 (2009) 839.

[19] M.E. Fragalà, G. Malandrino, O. Puglisi, C. Benelli, Chem. Mater. 12 (2000) 290.

[20] M.E. Fragalà, G. Compagnini, G. Malandrino, C. Spinella, O. Puglisi, Eur. Phys. J. D 9 (1999) 631.

[21] G.M.L. Messina, C. Satriano, G. Marletta, Chem. Commun. 40 (2008) 5031

[22] G. Malandrino, M. Blandino, L.M.S. Perdicaro, I.L. Fragalà, P. Rossi, P. Dapporto, Inorg. Chem. 44 (2005) 9684. 